\title{
Valimento, privança e favoritismo: aspectos da teoria e cultura política do Antigo Regime
}

Ricardo de Oliveira ${ }^{1}$

UFRJ

\section{RESUM O}

Na cultura política do Antigo Regime, em que inexista a separação entre as esferas públicas e privadas, o papel das relações interpessoais era determinante em qualquer projeto ascensional. Numa sociedade regulada pela lógica do favorecimento pessoal, a amizade tornavase elemento essencial. Nesse quadro emergem as personalidades marcantes dos'validos' ou 'privados' que se atrelam umbilicalmente ao centro do poder, chegando em muitos casos a desfrutar da centralidade da graça régia, o que lhes permitiu atuar decisivamente como instância de poder decisório. 0 Cardeal Richelieu, o Duque de Olivares e o próprio $M$ arquês de Pombal podem ser classificados como validos. Este artigo pretendediscutir algumas dimensões dessetraço pouco problematizado da vida política durante a Época M oderna.

Palavras-chave: Cultura política; Favoritismo; Patronagem.

\section{ABSTRACT}

In the political culture of the Ancien Ré gime, in which there was no division between public and private sectors, the role of the interpersonal relationships was prioritizing in any project of social upgrading. In a society ruled by the logic of personal favoring, friendship was an essential element. Outstanding personalities of the validos or privados emerge in this scenario and they are closely linked to the center of the power benefiting, in many cases of the royal mercy, which enabled then to act decisively as an instance of the ruling power. Cardinal Richelieu, Duke of Olivares and the $M$ arquis of Pombal can be classified as validos. This article aims at discussing some dimensions of this aspect of the political life during M odern Age.

Keywords: Political culture; Favoring; Patronage. 
A existência de indivíduos que orbitaram em torno da esfera central do poder e, mesmo não se constituindo, nestes casos, seus legítimos representantes, exerceram forte influência de decisão, não foi um atributo exclusivo das sociedades do Antigo Regime. Desde a Antiguidade - como podemos ver nas mais diversas fontes, como a Bíblia, passando pelos escritos de caráter histórico de Heródoto, Plutarco, Tucídides, Tito Lívio e Tácito - , a problemática, de alguma forma, foi recorrente, servindo até mesmo de fonte fundamental tanto para a crítica quanto para o elogio produzido pelos discursos políticos e tratados sobre a ética na Época M oderna acerca da presença dos validos na dinâmica da sociedade de corte. Porém, na sociedade contemporânea, conforme lembra Laurence Brockliss, o fenômeno é também percebido, sendo, de alguma maneira, algo atual o surgimento de personalidades que influenciam as decisões de poder de forma a lembrar a ação política dos validos. Seja na pessoa de consortes, amantes ou amigos, as chamadas "eminências pardas" continuam a influir no interior das democracias burguesas contemporâneas. ${ }^{2}$ Porém, pretendemos neste artigo discutir algumas dimensões desse fenômeno no âmbito da cultura e da teoria política do Antigo Regime, mais especificamente no contexto da Península I bérica.

Uma observação inicial que se deve realizar a respeito da problemática do valimento é que o assunto, até bem pouco tempo atrás, de certa maneira, passou despercebido, sendo a personagem do valido imaginada quase sempre negativamente, a partir de perspectivas historiográficas que viram no valimento uma anomalia no processo de construção do Estado. Por exemplo, em 1844, Lord M acaulay, à época escrevendo sobre o Conde de Bute, favorito primeiro-ministro do jovem rei Jorge III , dava o tom das críticas formuladas pela historiografia liberal acerca da figura do valido. Dizia ele que "os favoritos sempre foram odiosos neste país". ${ }^{3}$ Também no século XIX, novelistas como Walter Scott, Alexandre Dumas e Honoré de Balzac, seguindo os passos abertos por Lesage, nas Aventuras de Gil Blas, de 1715, como assinala John Elliot, recriaram o mundo dos validos como algo cada vez mais remoto, em que cortesãos disputavam o poder e maquiavélicos ministros- privados teciam complexas redes de intrigas em meio à corrupção e à intolerância. ${ }^{4} \mathrm{~N}$ o seu conjunto, estas representações passaram a fornecer elementos básicos para o que poderíamos denominar de anedotário da vida política do Antigo Regime, quase sempre fazendo eco aos juízos coevos que se posicionaram outrora negativamente em face do valimento. ${ }^{5} \mathrm{M}$ as, há outros fatores que explicam por que a historiografia no 0 cidente negligenciou o fenômeno do valimento na Época M oderna. Um dos mais lógicos resulta da hegemonia exercida pela his- 
tória social durante boa parte do século passado, a partir da luta travada pela Escola dos Annales contra as modalidades do discurso histórico que, marcadas pela inexistência de problematização, foram denominadas de história factual ou, pejorativamente, política do século XIX. Com isso, houve praticamente o esquecimento da biografia como gênero historiográfico sério, tendo sido relegada ao estatuto de investigação de segunda ordem, o que conduziu, portanto, a um longo eclipse dos estudos acerca das elites políticas modernas, bem como do papel complexo dos favoritos durante o período.

Consideramos pioneira, nesse campo, a abordagem feita pelo renomado historiador espanhol J osé Antonio M aravall, em 1944, na obra intitulada Teoria del Estado en España del siglo XVII, em que, mesmo tratando-se duma investigação na qual a preocupação central é realizar uma abordagem sistemática da teoria política ibérica no contexto da Contra-Reforma, o autor dedica todo um capítulo à discussão profunda sobre a literatura do período, no qual a teoria do consel ho e o problema dos ministros, dos secretários e do valimento foram imensamente debatidos no âmbito da teoria política hispânica. ${ }^{6} \mathrm{Na}$ trilha aberta por $\mathrm{M}$ aravall, outro importante historiador espanhol a tratar da questão, na década de 1960, foi Francisco Tomas y Valiente com o estudo seminal Los validos en la M onarquia española del Siglo XVII, em que centrou as preocupações de sua análise sobre as dimensões institucionais e administrativas da Espanha dos últimos três Áustrias, período áureo do valimento. ${ }^{7}$ Todavia, do ponto de vista de um tratamento mais próximo da sociologia histórica, em 1974, o historiador francês Jean de Berenger publicou na Revista dos Annales artigo em que propunha novo ol har sobre o que na sua opinião fora verdadeiramente um fenômeno da cultura política européia entre fins do século XVI e a primeira metade do XVII. ${ }^{8}$ Segundo Berenger, durante esse período, mais do que um fenômeno social isolado ou extemporâneo, o val imento fez parte da realidade histórica de várias monarquias européias, tornando-o um problema da maior relevância para a compreensão da época. D esta forma, a partir do alerta lançado por Berenger e de um novo significado que se atribuiu aos estudos biográficos e de história política, historiadores franceses, ingleses, italianos e espanhóis lançaram-se à investigação das diferentes perspectivas no quetange tanto à prática social do valimento quanto à trajetória de inúmeros validos. ${ }^{9}$

O conceito de valido é de origem castelhana e, apesar de não anotado por Sebástian de Covarrubias em seu Tesoro de la Lengua Castelhana o Española (1611), ${ }^{10}$ o termo foi muito empregado a partir do final do século XVI, ${ }^{11}$ passando a fazer parte do vocabulário corrente da cultura política ibérica como 
tradução para a idéia de al guém que se coloca sob a proteção de outro mais poderoso. No início do século XVIII, o Pe. Raphael Bluteau, no Vocabulário Português \& Latino, definia valimento como favor, poder, amparo, mediania do valido, e assim (como muitas vezes sucede) mais pode o valimento de um particular que o bem público. Bluteau registrou que o valido é "aquele que tem valimento, que pode com alguém mais do que os outros",12 assim:

são validos, olhos, \& orelhas do Príncipe, porque só por eles vem, \& ouvem os Príncipes. 0 que ensina a reinar, pode dizer que ele mesmo reina, o Valido, que com o Príncipe faz quanto quer, na realidade éo próprio Príncipe. Esta éa maior desgraça de um Reino, reduzir-Ihe toda a administração do Estado a um só, \& a um, que não é seu próprio senhor. Verdade é que não pode tirar a um Príncipea liberdade de escolher sujeito benemérito, em cuja capacidade descanse, tolher ao soberano levantar humildes, \& engrandecer pequenos, é tirar-Ihe da mão o cetro, $\&$ apagar a mais viva luz da sua Coroa, neste engrandecimento está interessada a Republica, porque é bem dela que se premiada a virtude. M as muitas vezes sucede que no favor dos Validos, como antigamente nas águas do Nilo, se ignore a sua origem. Lá o disse Antonio no Panegírico de Graciano, Rationem felicitatis memo reddit. Muito embaraçados se veriam muitos, se se vissem obrigados a declarar a causa da sua fortuna. ${ }^{13}$

Fruto de uma cultura política que poderíamos definir como a de uma sociedade que tinha no favorecimento e no clientelismo seu fundamento, 0 fenômeno do valimento era coetaneamente compreendido como parte integrante da dádiva régia. Neste sentido, o valimento, segundo Bluteau, colocarse-ia como pólo de concentração da graça e da benevolência régia. Como assinala esseautor, ao enunciar uma das definições para esteconceito queintegra o universo da antidora, "a graça de um Príncipe é um templo cuja porta são seus validos", porque estes "são os ol hos e as orelhas do Príncipe, porque por eles os Reis vêem e ouvem tudo". ${ }^{14}$ Todavia, como qualquer relacionamento baseado em laços unicamente pessoais e de amizade, no ambiente de disputas que marcou a vida da Corte no Antigo Regime, a instabilidade e o caráter efêmero da graça régia eram bastante freqüentes. 0 mesmo Bluteau registra esse aspecto central do valimento:

Causa principal do maior valimento talvez éa fantasia do M onarca. Pouca firmeza pode ter fundamento fantástico. Não se fie na bonança o sujeito engolfado no mar do valimento, só com os olhos no Céu poderá guiar bem o baixel das 
suas esperanças. As grandes ruínas estão sujeitas a fortunas grandes. As quedas dos Validos são precipícios, decaídos, não tornam a subir. Os Cortesãos de ordinária estatura, hora caem, \& hora se levantam; caiu o Anjo, \& caiu o homem, levantou-se o homem, não já o Anjo, porque na exaltação da fortuna, \& da gloria não era o homem tão sublime como o Anjo. No Teatro da grandeza humana, não achamos valimentos imortais, atribui esta impermanência de improsperidade ao Fado, Fato potentia, raro sempiterna. Testemunhas da instabilidade do valimento são os trági cos fins de Amão, Valido de Assuero; de Clito, Valido de Alexandre; deSejano, Valido de Tibério; Plauciano, Valido do Imperador Severo; de Álvaro de Luna, Valido de João II, Rei de Castela; do M ariscal de Biron, Valido de Henrique IV; do M ariscal d'Ancre, Valido de M aria de M edicis, Rainha da França, \& c. No 2. Tomo de seus Sermões, pág. 98, mostra o P. Antonio Vieira com mais nobre etimologia e chamam Privados. Valido do Príncipe. ${ }^{15}$

Todavia, tratando-se especificamente das sociedades do Antigo Regime, notamos que a origem dos validos é, até certo ponto, bastante diversa, quase sempre se explicando pelo fato de eles terem sido, durante os tempos de juventude do futuro monarca, príncipe ou governador, próximos a ele. N essas fases o jovem passava por um processo complexo de educação no qual, como é o caso da monarquia hispânica após o reinado de I sabel e Fernando, se procurou, a todo momento, isolar o príncipe das influências maléficas exercidas pelos partidos no interior da Corte. Buscava-se, assim, proteger o infante da ascensão sobre si de uma personalidade persuasiva. ${ }^{16} \mathrm{~N}$ esse sentido, a prática pedagógica que deveria orientar o jovem príncipe durante o período de preparo para a governação primava pela intenção de isolar o herdeiro das parcialidades que se formavam inevitavelmente na Corte no processo de disputa pelo monopólio do favor régio. Na chamada I nstrução Secreta, redigida por Carlos I a seu filho Felipe, em 1543, encontramos essa preocupação, que se repetiria futuramente, noutras ocasiões. ${ }^{17}$ Buscava-se a formação de um príncipe virtuoso, em que a prudência e a justiça fossem os pilares da ação e do pensamento político. Porém, o que se viu posteriormente na monarquia hispânica, em particular, e nas demais de forma geral, foi o surgimento e a afirmação de inúmeros validos que acabaram por concentrar sobre si monopólio do favor régio. M esmo Felipell, consagrado como Rei Prudente, tevevalidos perto desi.

Do ponto de vista de uma sociologia dos afetos, o valimento surgia quase sempre de relações pessoais teci das entre um jovem príncipe, inseguro e aberto a amizades, e alguém mais velho que, quando não era o próprio tutor 
responsável pela sua educação, se configurava na pessoa mais próxima e influente. M as não poucas vezes, por conta disso, foram os validos acusados de serem favorecidos por relações íntimas e de caráter sexual com os príncipes, o que os tornaria os mais próximos. Entretanto, não podemos esquecer que nessas configurações sociais, tais práticas estavam legitimadas pela própria natureza das monarquias modernas, em que, não é demais repetir, inexistia a separação das esferas pública e privada. 0 caráter pessoal das relações era, portanto, a regra do modus operandi dessas sociedades. Assim, o valimento inscrevia-se na própria demanda específica da estruturação política do Antigo Regime como espaço possível para a hegemonia de um grupo aristocrático sobre os demais, ou mesmo como forma de ascensão para sujeitos oriundos desetores não nobilitados da sociedade, em geral letrados, que por méritos e serviços obtinham a graça régia. Contudo, era essencial a amizade que se desenvolvia entre ambas as partes, regidas por um complexo código em que os afetos possuíam o poder de agir como elementos importantes no processo de coesão social. ${ }^{18}$ Esse é um elemento essencial para compreendermos a lógica do valimento na cultura política do Antigo Regime.

Uma constatação a que podemos chegar a partir de uma análise, mesmo que superficial, do conjunto desses estudos é justamente a pluralidade de opiniões acerca dos validos, que nos permitem perceber os depoimentos coetâneos. No campo específico da teoria política moderna, conviveram, lado a lado, juízos extremamente negativos e, ao mesmo tempo, verdadeiras defesas apologéticas acerca do privado do rei no interior da vida política das Cortes onde o fenômeno se fazia sentir. ${ }^{19}$ Ao longo do século XVI, por exemplo, pensadores como Maquiavel, Botero, Bodin e Lipsio - preocupados, cada um à sua maneira, em defender a legitimidade do poder real diante dos desafios lançados no processo de construção do Estado, a partir daquilo que compreendiam por ragione di stato - teorizaram bastante sobre a questão do papel dos privados ou validos no âmbito do exercício do poder. Como assinalou Antonio Feros, inicialmente a opinião hegemônica propalada no debate político quinhentista, especialmente na Península I bérica, era de que o exercício do poder em que o príncipe fazia a escolha por uma facção cortesã, ou mesmo, pelo aconselhamento de poucos privados, caracterizar-se-ia por certo perigo de colocar o Reino num conflito que resultaria na instabilidade e no fracasso do próprio monarca e do Reino.

Esses autores comungavam o desejo de alertar os príncipes sobre os perigos oriundos da preferência por um privado, e lançavam críticas sobre a demasiada proximidade dos monarcas em relação a algum protegido. M aquia- 
vel, no entanto, reconhecia a necessidade que tinha o príncipe de se cercar de "bons ministros - competentes e fiéis"; porém, advertia o célebre pensador florentino que o príncipe deveria ter cuidado com a excessiva autonomia desse privado. Isto é, o príncipe, quando percebesse "que o ministro pensa mais em si próprio" do que nele, "que em todas as suas ações procura tirar proveito pessoal", não deveria confiar nele, pois quem tem os negócios do Estado em suas mãos não deve nunca pensar em si próprio, e sim no príncipe. No intuito de garantir a eterna fidelidade desse ministro, o Príncipe deveria

pensar nele, fazendo-o rico, obrigando-o para consigo, fazendo-o participar de honrarias e cargos, de modo que as muitas honrarias não Ihe façam desejar outras, as muitas riquezas não Ihe façam desejar maiores, e os muitos cargos não Ihe façam temer mutações. ${ }^{20}$

M aquiavel, apesar de reconhecer a necessidade de o príncipe ter que, por vezes, recorrer ao consel ho de ministros ou de um privado, colocava-se bastante reticente quanto à ação destes, pois, em última instância, poderia ser o prenúncio da falta de autoridade régia. Da mesma forma, atacava frontalmente os aduladores, sugerindo aos príncipes que evitassem a ação persuasiva de um único indivíduo. Criticava tremendamente o exercício do poder em que o príncipe era suscetível à ação de privados ou ministros-favoritos que poderiam conduzir ao enfraquecimento da autoridade régia e levar o reino à instabilidade. ${ }^{21}$ Distante do posicionamento político de M aquiavel, outro importante personagem do humanismo europeu, Erasmo de Rotterdam, em 1516, terminava mais uma obra de caráter pedagógico, Institutio Principis Christiani (Educação do príncipe cristão) - dedicada a Carlos I de Espanha para que pudesse servir de manual para melhor educar seu herdeiro. Nela dizia que 0 monarca verdadeiramente prudente deveria procurar evitar os aduladores sobre seu herdeiro, demonstrando perfeitamente esta premissa na cultura política que orientava o sentido da pedagogia dirigida a formar o perfeito príncipe cristão, pois os aduladores poderiam "corromper o caráter do futuro príncipe"..22

De outro ponto da teoria política da ragione di stato, lugar esse declaradamente contrário ao maquiavelismo, o pensamento político católico do século XVI também colocou inúmeras objeções à presença do privado junto à esfera mais íntima do poder. 0 mais destacado entre os pensadores católicos do período, Giovanni Botero, em sua D ella Ragion di Stato, publicada em 1589, muito importante na cultura política do período - tendo conhecido inúme- 
ras edições e traduções - , apesar de também aceitar a necessidade da existência de conselheiros - pois, conforme dizia, "não convém ao Príncipe administrar a justiça e pronunciar as sentenças pessoalmente, é necessário que encontre ministros capazes e honestos que façam isso por ele",$-{ }^{23}$ na prática era radicalmente contra a presença de favoritos. Na sua opinião, a escolha de um privado poderia evidenciar a debilidade do monarca, o que poderia dar ao favorito a oportunidade de usurpar o trono - perigo que assombrava aqueles que pensaram o valimento. Ou seja, era fundamental que o Príncipe nunca deixasse aos seus ministros, por maiores que fossem, “o arbítrio ea faculdade absoluta de administrar a justiça", ${ }^{24}$ caso contrário à própria instituição monárquica estaria vulnerável e em perigo. ${ }^{25}$

Na mesma época, no âmbito ainda da cultura política católica, a esse respeito compartilhavam opiniões semel hantes outros dois destacados teóricos do Estado: Jean Bodin e Justo Lipsio. Q uase que simultaneamente, as obras desses dois autores faziam coro com Botero no sentido de apontar os perigos e mal efícios que poderiam ser causados pela ação de privados. Jean Bodin, em 1576, publicava Les six livres de la Republique, obra que foi acusada por alguns de promover 0 ateísmo, pois nela se defendia o direito divino dos reis, mas que teve ampla circulação na Europa católica. Seu autor severa crítica à prática da privança, apontando para a sua periculosidade enquanto forma de enfraquecimento e vulnerabilidade da própria monarquia, defendendo uma teoria do poder político tido como absoluto. ${ }^{26}$ Por sua vez, o humanista Justo Lipsio, que na Península I bérica, durante as últimas décadas do século XVI, exerceu enorme influência com a obra Policorum sive civilis doctrinae libri sex, qui ad principatum maximespectant, publicada em Leiden no mesmo ano da obra de Botero, 1589, igual mente condenava a priori a existência de privados ou mesmo de conselheiros junto à esfera do exercício do poder. ${ }^{27}$ De certa maneira, a melhor forma de governo defendida por esses autores foi resumida por Lipsio recorrendo à seguinte tese:

la principal fuerza y honra no solo proceda del príncipe, sino que se esta cerca de el. Digo del principe, para que despache los mayores negocios el mismo, 0 al menos los ratifique y apruebe, firmándolos, por no enflaquecer el vigor del principado con remitirlo todo al Senado y consejos. No porque desprecie los consejos, pues los he persuadido con muchas veras, sino por desear que todo el mundo entienda que es el principe de quien dependen todos. El solo ha de ser juez y arbitro de las cosas por derecho y nombre de rey. Los reyes, que son senores de los negocios y tiempos, no si eguen los consejos, si bien tiran a si todas las cosas 
con ellos. Si algo se suelta de esto, el todo se pierde. Tal es la condicion del imperio, que no se puede mantener si no es remitido a un solo. ${ }^{28}$

Na Espanha de Felipe II, partilharam de opiniões semelhantes figuras influentes no plano intelectual como Pe. Pedro de Ribadeneira e o Jesuíta Juan de M ariana. Em seu Tratado de la Religión y Virtudes que debe tener el Príncipe Cristiano para gobernar y conservar sus Estados. Contra lo que N icolas M aquiavelo y los políticos de estetiempo enseñan (1595), Ribadeneira mostrava-se extremamente reticente acerca da presença defavoritos, da mesma forma Juan de M ariana em sua De rege et Regis instituione (1599), em que, guiado por princípio ético tomista, identificava os validos com os adulares, os favoritos que faziam quase sempre com que o monarca se afastasse do resto do corpo místico que se constituía afinal na integralidade do Reino, levando-o a cometer injustiças e arbitrariedades. Um traço interessante nesses ataques era a recorrência em citar um acontecimento do passado hispânico, em que, durante o reinado de Juan II, seu favorito, Álvaro de Luna, teria sido o pivô de uma verdadeira guerra civil no seio da corte. Esse fato tornou o reinado de Juan II um dos mais conturbados de que se teve notícia, tendo entrado para a memória da cultura política ibérica como exemplo do caráter pernicioso da ação dos privados. ${ }^{29}$

H avia, porém, uma série de discursos em que se advogava a existência de privados, procurando legitimar a sua presença junto à realeza, sendo este outro traço importante da cultura humanista. Existiu a idéia segundo a qual os humanistas de uma forma geral pensavam-se como os mais acertados conseIheiros para os príncipes. Isto é, na consciência de inúmeros humanistas - a par da polêmica sobre o sentido do otium sobre o negotium, já que supor que um filósofo assumisse a rédea da República era algo impensável - dever-seia incentivar que os reis e príncipes, além de uma educação apropriada que bem os formasse dentro dos padrões éticos da virtude cristã, tivessem ao seu lado um conselheiro - na figura de secretários ou ministros - que agisse como verdadeiro farol para sua consciência. ${ }^{30} \mathrm{O}$ u seja, na imensa literatura surgida entre os séculos XVI eXVII com a intenção de melhor conduzir a formação do príncipe, ao lado das reservas quanto à excessiva influência dos conselhos ou de ministros privados, sempre existiram formulações que viam positivamente a existência e a prática da privança. ${ }^{31}$ N esse mesmo gênero foram importantes também as obras de Juan Luis Vives, Jacobo Sadoleto, Roger Ascham, Josse Clichtove, Frei Jerônimo O sório, Felipe de la Torre e Francisco de M oncon, somente para citarmos as mais conhecidas referências que abrange- 
ram tanto a Europa setentrional quanto a meridional, onde a questão foi, reiteradas vezes, pensada e discutida. ${ }^{32}$

$\mathrm{Na}$ Europa meridional católica produziu-se uma grande quantidade de discursos positivos sobre a legitimidade de um tipo muito importante de privado ou valido - o secretário. Na Península Itálica, terra de M aquiavel, lugar onde se respirou com intensidade o forte ar da cultura do humanismo renascentista, surgiram vários desses discursos desde a primeira metade do século XVI, praticamente todos seguindo os passos de Bal dassare Castiglione no seu Il libro del cortegiano, de 1528. 0 caso mais importante talvez seja 0 Príncipe, de Giovan Battista Nicolucci, publicado pela primeira vez em Veneza, no ano de 1561. Trata-se de uma obra que, após ter sido aumentada pelo seu editor, Francesco Sansovino, teve várias edições até 1608. Fornece, certamente com intenções autopromocionais, áridos argumentos contra a velha nobreza, propalando o sentido aristocrático dos secretários letrados, vistos como verdadeiras costelas dos príncipes, transformando o secretário de funcionário em conselheiro-privado, uma espécie de anjo do seu senhor. Partindo de modelos fornecidos pela tradição da oratória clássica a partir dos modelos de Aristóteles, Cícero e Quintiliano, ${ }^{33}$ por exemplo, produziu-se uma imensa literatura que, desde então, legitimou o papel do secretário e suas atribuições como sujeito que, por seus méritos, mereceria o privilégio de compartilhar com os príncipes os segredos e o poder. ${ }^{34}$

Voltando a falar especificamente do Mundo Ibérico, podemos dizer que ali a questão do valimento assumiu proporções gigantescas e, paralelamente às concepções, por assim dizer, negativas acerca do papel político dos conseIhos, conselheiros régios, privados e validos, foram inúmeros os textos que legitimaram o papel desempenhado pelos validos, em certos casos, de forma verdadei ramente apologética. Ainda na primeira metade do século XVI, Antonio de Guevara, em Avisos de privados, obra publicada em 1539, e, mais tarde, Fadrique Furio Ceriol, em El Consejo y Consejeros del Príncipe, de 1559, já haviam apontado para esse posicionamento, que se tornaria bastante comum na cultura política castel hana posteriormente, sinalizando para a necessidade e legitimidade da instituição do consel ho junto à esfera central da governação. Fadrique Furio Ceriol afirma, logo no início de seu pequeno tratado, que:

Es el Concejo para con el Príncipe como casi todos sus sentidos, su entendimiento, su memoria, sus ojos, sus oidos, su voz, sus pies i manos: para con el pueblo es padre, es tutor i curador: i ambos, digo el Principe i su Concejo, son Tenientes de Dios acá en la tierra. De aquí se siegue, que el buen Concejo da per- 
fecto ser i reputación a su Principe; sustenta i engrandesce al pueblo; i los dos, digo el Principe i su Concejo, son buenosi leales ministros de Dios..$^{35}$

Ou seja, parte de uma concepção que compreende a ordem monárquica como uma instituição natural criada por Deus, possuidora em sua essência de um princípio através do qual o Príncipe visto como primo inter pares deveria contar sempre com uma espécie de governo compartilhado. Neste ponto, a teoria dos conselhos se estabelece, oferecendo uma al ternativa bastante atrativa contra o maquiavelismo individualista e autocrático na condução do poder. Através dos conselhos, a nobreza situava-se de forma legítima no centro do poder, afastando o perigo da tirania. Falavam especificamente sobre o papel dos validos ou privados, oriundos ou não dos conselhos - apesar de o próprio Felipe II ter contado durante os últimos anos de seu reinado com a ação de Cristóvão M oura, identificada como um modelo de valimento. Somente a partir do reinado de seu sucessor a questão assumiu uma dimensão em que, da prática social recorrente do valimento no interior da governação, produziu-se uma quantidade enorme de discursos e tratados que legitimaram o valimento.

Em 14 de setembro de 1598 morria Felipe II , conhecido como Rei Prudente. $\mathrm{E}$ o que muitos na Corte temiam aconteceu: a ascensão de Dom Francisco Gomes de Sandoval y Rojas, V M arques de Denia, IV Conde Lerma a partir de 1575 e Duque de Lerma desde 1599, como valido e privado no jovem rei Felipe III. Na opinião de Tomas y Valiente, a partir daquele momento se institucional izava a prática do valimento ${ }^{36}$ no âmbito da monarquia espanhola. M ais do que isso, nas duas décadas seguintes praticamente todos os negócios da monarquia deveriam passar pelas mãos do valido. Tempos depois, o próprio rei fez questão de enviar ao Conselho de Estado uma nota onde resumia o caráter do valimento do Duque:

Desde que conozco al duque de Lerma le he visto servir al rey mi señor y padre, que aya gloria, y a mí con tanta satisfacción de emtrambos que cada día me hallo más satisfecho de la buena quenta que me da de todo lo que lo encomiendo y mejor servido dél; y por esto, y lo que me ayuda a llevar el peso de los negocios, os mando que cumplais todo lo que el duque os dixere o ordenare, y que se haga lo mismo en ese Concejo, y podársel e también decir todo lo que quisiere saber dél, que aunque esto se ha entendido así desdeque yo subcedí en estos Reynos, os lo he querido encargar y mandar agora. ${ }^{37}$ 
Como assinalou Francisco Tomas y Valiente, esse documento representou o mais claro reconhecimento, escrito por um dos últimos Áustrias, acerca da intervenção do valido na governação da monarquia e, por assim dizer, a mais ampla concessão de poder e mando a um privado..$^{38} \mathrm{O}$ paradigmático estudo de Antonio Feros sobre a privança do Duque de Lerma aponta para o processo através do qual, em torno de seu valimento, os Sandoval conheceram um processo ascensional em que se operou um gigantesco acrescentamento no prestígio e patrimônio de sua Casa. Formou-se uma rede complexa de nepotismo, patronagem e clientelismo que assegurou a hegemonia dos Sandoval..$^{39}$ A partir do valimento do Duque de Lerma, a prática do valimento tornou-se presente no âmbito da M onarquia I bérica, possibilitando a determinados setores da nobreza castel hana certo controle da esfera íntima do poder e centralidade na preferência da graça régia. ${ }^{40}$

A partir de 1618 iniciou-se o desprestígio de Lerma, e seu filho U ceda viria a sucedê-lo, mesmo que efemeramente, como privado de Felipe III. Contudo, após a morte do monarca, em 1621, dá-se definitivamente o ocaso no poder dos Sandoval ${ }^{41}$ Com a coroação do novo monarca, Felipe IV, o mundo ibérico veria a ascensão do novo e grande valido: o Conde-Duque de Olivares, D om Gaspar de Gusmán, quando, por assim dizer, a prática política do valimento conheceu o apogeu. Verdadeiro timoneiro de uma complexa configuração de poder monárquico transnacional, Olivares enfrentou as tempestades de convulsões sociais internas e separatismos que iam da Catalunha a Portugal, além dos momentos mais dramáticos da Guerra dos Trinta Anos.

Durante esse período, no campo do discurso e da teoria política, a questão dos validos conheceu uma quantidade bastante significativa de autores que advogavam sua legitimidade e importância. Somente para exemplificação, dentre os vários títulos passíveis de análise, todos surgidos na mesma época, destacamos: Discurso del Perfecto Privado, de Pedro de Maldonado (1609); Secretario y Consejo de Senores y M inistros, de Gabriel Perez del Barrio (1613); Del Senado y su Principe, de Fr. Juan de M andariaga (1617); Consejo y Consejeros de Príncipes, de Lorenzo Ramirez de Padro (1617), e El Secretario del Rey, de Francisco Bermudez de Pedraza (1620). Francisco de Quevedo dedicou ao tema uma comédia, Como ha de ser el Privado, não poucas vezes posta em cena na mesma época. 0 conhecido pensador político espanhol Diego Saavedra Fajardo, em sua Ideia de un Príncipe político Christiano, Representada en cien Empresas - obra publicada pela primeira vez em 1640, quando ainda preponderava Olivares na vida política espanhola - , dedicou algumas páginas à apologia e ao depoimento em favor da existência dos 
validos. ${ }^{42}$ Em 1641, Fr. Jose Laynez publicava também uma obra de defesa do valimento, El Privado Christiano, deducido de lãs vidas de Joseph y Daniel, que furem balanzas de los Validos en el fiel contraste del pueblo de Dios, em que os exemplos bíblicos eram levados ao seu nível mais elevado no intuito de demonstrar a justeza com a qual o monarca deveria velar pelos seus privados. De certa maneira, o valimento estava inscrito na própria ordem natural e, portanto, jamais deveria o monarca prescindir de sua presença.

No conjunto desses escritos, a questão da teoria do consel ho é central em todo o debate, pois foi em torno dela que a questão dos validos ou privados se colocou de maneira clara e tremendamente interessante. M aravall resumiu a questão dizendo que o consel ho foi uma peça fundamental na construção política do Estado, que se apoiou basicamente na legitimidade de um aristocratismo intelectual herdado do humanismo e que se impôs como uma solução possível para apoiar o monarca no exercício de sua soberania. Isso explica a existência de inúmeros livros que se dedicaram a estudar a teoria do conselho durante o período. ${ }^{43}$

Os discursos legitimadores dessa esfera de exercício do poder alicerçavam-se fundamentalmente nos textos bíblicos e na tradição tomista-aristotélica, definindo que, assim como em outras esferas da existência humana, era algo natural a presença de conselho junto ao rei no sentido de guiá-la rumo à prudência. Apesar de severo crítico do valimento, o Pe. Pedro de Rivadeneira, no tratado escrito para refutar as teses de M aquiavel, anotava que o príncipe deveria ter sempre presente em sua consciência que para realizar as coisas que convinham à boa governação do reino havia a necessidade de, como ele mesmo diz, contar com "muchos vireyes, presidentes, embajadores y ministros", e, mais importante ainda, nesse sentido, para que pudesse compreender "todas las cosas por si mismo", deveria absolutamente ter quem 0 aconselhasse. ${ }^{44}$ $M$ as uma das defesas mais expressivas encontramos em Fr. Juan de $M$ andariaga. Em 1617, justificava essa necessidade pelo fato de se ter que reconhecer o caráter falho da ação humana:

Tiene el hombre esta necesidad de su propia cosecha, esto es, de ser naturalemente imperfecto en el orden de las criaturas intelectuales, que son los ángeles y los hombres, de tal manera que, aunque permaneciera en el estado de la natureleza entera, sin pecar, por cuanto ni él fueron los hombres de igual ingenio y capacidad, tuvieran siempre los menores esta necesidad del consejo y dirección de los mayores. Vienele a la naturel eza humana esta imperfección, de estar unida con el cuerpo y serle por esto necesario haberse de volver a considerar las cosas 
corporales para conocer las intel ectuales ya sacar poco a poco de una cosa bien entendida el conocimiento de otra que no se sabe. ${ }^{45}$

Devemos ter como referência que esses argumentos, que buscavam legitimar a presença do consel ho junto à esfera da governação do reino, assentavam-se nos pressupostos do constitucionalismo neotomista que foi uma das tendências principais da teoria política católica desenvolvida na Península I bérica da Contra-Reforma, a partir das últimas décadas do século XVI, e que tevenos escritos do jesuíta Francisco Suárez o momento mais elevado de construção especulativa. Estes insistiam na tese de que o poder político era essencialmente temporal, fruto de uma delegação natural dada pela sociedade ao soberano e que, portanto, de natureza contratual, era algo instituído pelos homens como forma de possibilitar o bem comum. ${ }^{46} \mathrm{Assim}$, contar com a participação de outros junto a si fazia do príncipe, nessa perspectiva, o maior zelador pela harmonia e paz da comunidade.

Observe-se que, não por mero acaso, essa verdadeira profusão de defesas acerca da prática do valimento na cultura política que estamos analisando, bem como a tentativa de sua normatização do ponto de vista institucional, pedagógico, além da própria simbolização do valido como a imagem e semeIhança do Rei, acompanharam na Espanha o período compreendido entre os reinados de Felipe III e Felipe IV, quando houve a hegemonia de Francisco de Sandoval, Duque de Lerma, e depois de Gaspar de Gusmán, Conde-D uque de Olivares, nessa que pode ser considerada a época áurea dos validos.

Caracterizada pela historiografia decadente e conflituosa, marcadamente urbana e conservadora, ${ }^{47}$ esse período assinala efetivamente, não apenas no âmbito do mundo ibérico, a crescente complexidade de gestão da máquina governativa. N esse sentido, a prática do valimento veio atender a uma necessidade nova do processo de construção do Estado no âmbito institucional. Através do fenômeno do valimento, conheceu-se o processo de construção de uma das primeiras formas de propaganda dirigida de forma ampla, visando legitimar tanto a figura dos validos quanto a do próprio monarca. À sombra do rei, essas peças tornavam evidente o caráter novo da política.

Na mesma época, em Portugal, Bartolomeu Pachan dizia ser da própria condição humana a necessidade de o príncipe contar sempre com o auxílio de ministros. ${ }^{48}$ E João Pinto Ribeiro, no Lustre ao Desembargo do Paco, fazia um discurso argumentando sobre a importância de tais serviços que a nobreza deveria prestar através de uma relação de amizade ${ }^{49}$ para com o monarca. Neste sentido, o rei não deveria, de modo algum, prescindir de contar com o 
conselho para bem governar. Falava-se insistentemente da necessidade de ter bons conselheiros, quase sempre identificados com os chamados secretários. No Tesoro, Covarrubias traduzia o juízo coevo acerca do papel social do secretário, dizendo que era "oficio de mucha confiança cerca de los reyes y sus consejos, em todos los tribunales y entre señores particulares". ${ }^{50}$ Pela mesma época, aproximadamente em 1620, Francisco Bermudez Pedraza, valendo-se da imagem que identifica a monarquia com o corpo místico, discursa para legitimar essa necessidade natural na arquitetura do Estado:

La mayor parte de la grandeza del secretario consiste, Senor, en la necessidad queV. M. Tiene de su persona, porque quanto mas soberano senor, y monarca mas poderoso, tanto mas necesita de secretarios, arcaduces por donde comunica a sus Reynos el gobierno... Porque si V. M. Es la cabeça, sus Secretarios son la garganta del cuerpo mistico desta M onarquia; y por este cuello comunica a los demas miembros de sus Reynos el alimento de su gobierno; son el interprete de su voluntad, porque llevan al Principe las suplicas del Reyno... Son la voz del Principe, lo pronuncia el Secretario. Son la imagen de su coraçon ... Son los Secretarios la lengua con que el Principe habla a sus Reynos. ${ }^{51}$

A história nos mostra que, entre os séculos XVI e XVII, inúmeros foram os personagens que se enquadraram na definição de validos, privados e secretários-privados, entre outros títulos, e que exerceram influência e poder no jogo político da balança européia. O s cardeais Richelieu e M azarino, na França, o Duque de Lerma e o Conde-Duque de Olivares, na Espanha, e o Duque de Buckingham, na Inglaterra, são os casos mais conhecidos e estudados pela historiografia. Como já se fez notar, o Estado não era uma estrutura de poder fechada. No seu interior digladiavam-se setores aparentemente antagônicos, mas que convergiam no sentido de garantir a perpetuação daquela figuração social conhecida. 0 valimento podia servir tanto para a concentração de mais prestígio e privilégios entre setores da nobreza tradicional quanto para a ascensão de setores não nobilitados.

Em suma, sendo percebido negativa ou positivamente, o certo é que durante o processo de construção do Estado Moderno a figura do valido inscreve-se na própria lógica do poder, sendo possível, em muitos casos, nele perceber o papel de mediador entre o poder real e os grandes da nobreza, que 0 assediam. Porém, os validos operavam dentro dos padrões da cultura política do clientelismo, isto é, a economia da graça, pois muitas vezes foram os validos monopolistas em receber edistribuir favores reais, situando-se quase sem- 
pre no centro de uma grande rede de clientelagem. Para tanto, as práticas de valimento tinham como formas de ação os canais institucionais formalizados..$^{52} \mathrm{M}$ as também é possível imaginarmos que uma outra explicação possível para a emergência do fenômeno advenha da necessidade de se encontrarem soluções para a crise de crescimento do Estado, isto é, como assinala A. A. Thompson,

A crescente complexidade do Estado que, com a expansão das suas esferas de intervenção, estava desbordando os métodos pessoais de governo, havia acumulado uma carga demasiado pesada para um homem só, especialmente para um príncipe educado para a corte e não para o despacho. ${ }^{53}$

Havia, portanto, a necessidade do valido, pois este poderia atuar verdadeiramente como mediador no ambiente tenso e repleto de disputas que caracterizou na maioria das vezes a sociedade de corte do Antigo Regime. $\mathrm{Na}$ maior parte das vezes, o valido possuía o monopólio dos privilégios, da atenção e do favor real, ${ }^{54}$ e acabava captando para si os ódios e as paixões inerentes à trama da governação, on de inexista a separação entre as esferas pública e privada. Como notou Saavedra Fajardo, "cae sobre el valido toda la culpa a los ojos del mundo; y por no parecer el príncipe el autor de la maldad". ${ }^{55} \mathrm{Nes}$ te sentido, seguindo ainda a hipótese aventada por A. A. Thompson, "ele poderia servir como instrumento de supressão das facções", possibilitando até certa "unificação da corte" durante determinado período. ${ }^{56}$ Q uevedo, em sua comédia Cómo ha de ser el Privado, referida há pouco, através da fala do rei Don Fernando de Nápoles, personagem que simboliza na verdade Felipe IV de Espanha, protetor deD. Gaspar de Gusmán, Conde-Duque de Olivares, corroborando nossos argumentos, faz o seguinte discurso:

Para aliviar este peso

he menester un valido.

Rey que de nadia se fia,

Poco vale, y vale menos

El que de todos se fia.

Deun hombremehe de fiar...

0 temor maior, mesmo para aqueles que mais defendiam a legitimidade do valimento, relacionava-se justamente à possibilidade de o valido, aproveitando a inércia e incapacidade do príncipe, concentrar um poder enorme, 
corrompendo-se, epecar pela vaidade e pela soberba, algo que inevitavelmente conduziria a monarquia à instabilidade. Por isso, o valido, por mais poderoso que fosse, deveria manter-se sempre atento à temperança, cultivando a modéstia, a afabilidade e a gratidão àquele que lhe permitira tamanha fortuna. ${ }^{58}$ O utro traço complexo que marca o fenômeno dos validos éo aspecto reformista de sua ação política, num momento em que o Estado caminhava, como vimos, no sentido de instituir uma máquina administrativa eficiente e racionalizada. No limiar de uma prática em que a burocracia não conhecia ainda a separação entre as esferas pública e privada, o valido muitas vezes de forma autoritária tornava-se o agente desse processo de racionalização do poder, concentrando sobresi inúmeras demandas, bem como as críticas que poderiam ser direcionadas ao monarca. No jogo político que caracteriza todo esse processo, o valimento desempenhou uma função importantíssima enquanto instrumento demediação, tornando possível ao rei, muitas vezes, exercer de forma mais satisfatória o seu poder. 0 perfeito valimento pressupunha ser prudente e, acima de tudo, guardar segredo e gratidão, evitando a adulação. I mplicava a demonstração de eterna humildade em atribuir ao príncipe todos os acertos, sabendo sempre que o valimento é uma condição passageira e instável..$^{59}$

O valimento inscreve-se no próprio processo de construção do Estado, seja no plano institucional e ideológico, seja no da cultura política do Antigo Regime, de forma mais abrangente. $\mathrm{E}$ a longevidade do fenômeno, bem como a sua metamorfose, são questões importantes para a investigação histórica. Seja como possibilidade ascensional para elementos provenientes de setores não nobilitados da sociedade, seja como uma última trincheira para a manutenção dos privilégios da nobreza numa época de profundas transformações, ou mesmo como resultado da necessidade que tinham os monarcas de encontrarem verdadeiros mediadores ante os conflitos inerentes à sociedade de corte, o certo é que através do valimento, em larga medida, exerciase o poder político. U ma condição fundamental para a configuração social da prática do valimento, como definiu perfeitamente Tomas y Valiente, deve ser identificada a partir do pressuposto de que o valido, favorito ou privado conquistava esta qualidade social através da afetividade; "com amabilidade, astúcia" para fazer valer seus ansei os e projetos, mas servindo fielmente à vontade do soberano. ${ }^{60} \mathrm{M}$ as esta é uma discussão que por si só merece atenção.

Em suma, poderíamos concluir por hora que, inversamente ao que a historiografia marcadamente liberal quis sempre demonstrar, estigmatizando a percepção acerca da trajetória dos validos, acreditamos ser esta uma dimen- 
são que serve para apontar o caráter complexo do exercício do poder monárquico no Antigo Regime em que, longe da imagem de soberanos absolutistas e tirânicos, a esfera central de poder foi sempre mediada e preenchida por uma prática política que via como inerente à ordem natural das coisas a supremacia das relações afetivas entre os elementos sociais como os verdadeiros construtores do ordenamento social do poder político. Como elementos que praticamente monopolizavam a graça e a benevolência régia, o validos construíram muitas vezes, a par dos amores e ódios, trajetórias em que o exercício do poder foi algo distante da imagem de um soberano governando sozinho e autocraticamente. De forma bastante preliminar, devemos ter presente ainda que, na mai oria das vezes, esses atores políticos foram verdadeiramente expressão da chamada Realpolitik, para usarmos uma categoria mais próxima do universo das ciências sociais contemporâneas. Através da prática do valimento a máquina burocrática do Estado em construção encontrava um ponto de mediação, no qual o soberano poderia apoiar-se. Assim, nessa cultura política construíam-se princípios que, futuramente, serviriam para legitimar a própria condição do primeiro-ministro no plano institucional.

\section{NOTAS}

${ }^{1}$ Doutorando pelo Programa de Pós-Graduação em História Social (PPGHIS), da Universidade Federal do Rio de Janeiro (UFRJ), no Instituto de Filosofia e Ciências Sociais. A pesquisa de doutoramento, realizada no Brasil, Portugal e Espanha, contou com o financiamento da Capes. E-mail: rdoclio@aol.com.

2 BROCKLISS, L. "Anatomia del M inistro-Favorito". In: ELLIOT, J.; BROCKLISS, L. (Org.) El Mundo de los Validos. Madrid: Taurus, 1999, p.398.

${ }^{3}$ M ACAU LAY, L. "The Earl of Chantham. Essays and Biographies'. In: The CompleteWorks of Lord M auculay. London: Albany, v.XII, p.315. Citado em ELLIOT \& BROCKLISS (Org.)., op. cit., p.9.

${ }^{4}$ ELLIOTT, J. In: ELLIOT \& BROCKLISS (Org.), op. cit., p.11.

${ }^{5}$ FEROS, A. "I magenes de M aldad, I magenes de Reyes: Visiones del Favorito Real y el Primer M inistro en La Literatura Política de la Europa M oderna". In: ELLIOT \& BROCKLISS (Org.), op. cit., p.293-320.

${ }^{6}$ M ARAVALL, J. A. Teoria del Estado en España del Siglo XVII. Madrid: Centro de Estudios Constitucionales, 1995. 
7 TOM AS Y VALIENTE, F. Los Validos en La M onarquia Española del Siglo XVII. M adrid: Instituto de Estudios Politicos, 1963.

${ }^{8}$ BEREN GER, J. "Por une enquete europeenne: le probleme du ministeriat au XVIIe. Siècle". In: Annales, n.29, 1974, p.166-92.

${ }^{9} \mathrm{~A}$ bibliografia sobre o tema é expressiva nas línguas inglesa, espanhola, francesa e italiana, sendo praticamente inexistente em língua portuguesa. Além das obras já citadas, indicamos ainda: BENIGN O, F. L'O mbra del Re. M inistri e Lota Política nella Spagna del Seicento. Venezia: Marsilio, 1992; ea obra monumental de John Elliott sobre o Conde-Duque de Olivares. EllIOTT, J. H. El Conde-Duque de O livares. El Político en una época de decadencia. Barcelona: Grijalbo Mondadori, 1990.

${ }^{10}$ COVARRU BIAS H OROSCO, S. de. Tesoro de la Lengua Castellana o Española. Barcelona: Ed. Alta Fulla, 1998, p.561. (Ed. fac-similar.)

${ }^{11}$ Antônio Hauaiss, no seu Dicionário da Língua Portuguesa, registra que o termo 'valido', no sentido que iremos empregar aqui, apareceu na língua portuguesa em torno de 1572, usado por Camões em Os Lusíadas.

${ }^{12}$ BLUTEAU, Pe. R. Vocabulário Português \& Latino. Coimbra: Colégio das Artes da Cia de Jesus, Tomo IX, 1713, p.314.

${ }^{13}$ I bidem, op. cit., p.314.

${ }^{14}$ I bidem, op. cit., p.314.

${ }^{15}$ I bidem, op. cit., p.314.

${ }^{16}$ FEROS, A. El D uque de Lerma. Realeza y Privanza en la España deFelipe III. M adrid: M arcial Pons, 2002, p.39-74.

${ }^{17}$ Op. cit., p.39-74.

${ }^{18}$ CARDIM , P. 0 poder dos afetos. Ordem amorosa e dinâmica política no Portugal do Antigo Regime. Lisboa: Universidade Nova de Lisboa, 2000. (Tese de Doutoramento) / "Religião e O rdem Social. Em torno dos fundamentos católicos do sistema político do Antigo Regime". In: Revista deH istória da I déias. Coimbra: Instituto de H istória e Teoria das I déias, Faculdade de Letras da Universidade de Coimbra, v.22, 2001, p.133-74.

${ }^{19}$ Ver: MARAVALL, J. A., op. cit.

${ }^{20}$ M AQUIAVEL, N. O Príncipe. São Paulo: Abril Cultural (col. Os Pensadores), 1973, p.103-

4. (Cap. XXII.)

${ }^{21} \mathrm{~A}$ crítica aos aduladores não se encerrou com M aquiavel. Praticamente todos os pensadores políticos do período moderno fizeram seus ataques a esses personagens. Para uma 
boa exposição a esse respeito, ver: STARO BI NSKI, J. "Sobre a Adulação". In: As máscaras da civilização. São Paulo: Companhia das Letras, 2001, p.57-85.

22 ERASM O DE ROTTERDAM . Educación del Príncipe Cristiano. M adrid: Tecnos, 2003, p.87. Ver ainda: FEROS, A. El Duque de Lerma.., op. cit., p.41.

${ }^{23}$ BOTERO, J. Da Razão de Estado. Coimbra: IN IC/Centro de História da Sociedade e da Cultura da Universidade de Coimbra, 1992, p.24.

${ }^{24}$ Ibidem, op. cit., p.28.

${ }^{25}$ Para uma análise ampla da doutrina da razão de Estado no âmbito da história das idéias políticas, ver: M EINECKE, F. La Idea de la razon de Estado en la Edad M oderna. M adrid: Centro de Estudios Constitucionales, 1983. FERNÁN DEZ-SANTAM ARIA, J. A. Razon de Estado y politca en el pensamiento español del barroco (1595-1640). M adrid: Centro de Estudios Constitucionales, 1986.

${ }^{26}$ Na tradução castelhana da obra de Jean Bodin, publicada em 1590, o tradutor, Gaspar de Anastro Ysunza, anotou que a presente versão estava "emendada catolicamente", na intenção explícita de assegurar sua legitimidade perante o publico leitor ibérico. Ver: BODINO, J. Los seis libros de la Republica. Turin: Por Herderos de Bevilaqua, 1590.

${ }^{27}$ Tremendamente influente na Península I bérica, Justo Lipsio (1547-1606) foi responsável pela edição das obras de Tácito, em 1574. Tornou-se a principal referência do chamado neoestoicismo em fins do século XVI. Além da citada Politicorum, traduzida para o casteIhano por Bernardino de M endonza e publicada em 1604, D eConstantia, de 1583, um guia para os tempos de intolerância religiosa que conheceu cerca de oitenta edições em menos de um século, e D e M itia Romana, de 1595, são as referências fundamentais para a obra política de Lipsio. Sobre a importância da obra de Lipsio, em Portugal e Espanha, ver: ALBU QUERQUE, M . Um percurso da Construção ideológica do Estado. A Recepção lipsiana em Portugal: estoicismo e prudência política. Lisboa: Q uetzal Ed., 2002, eTORGAL, L. R. I deologia Política e Teoria do Estado na Restauração Portuguesa. Coimbra: Biblioteca Geral da Universidade, 2v., 1981-1982; M ARAVALL, J. A., op. cit.

${ }^{28}$ LIPSI O, J. Políticas. M adrid: Tecnos, 1997, p.134-5.

${ }^{29}$ FEROS, A. El Duque de Lerma..., op. cit., p.39-74.

${ }^{30}$ SKIN N ER, Q . Los Fundamentos del Pensamiento Político M oderno. M éxico: Fondo de Cultura Económica, v.l, 1993, p.239-47.

${ }^{31}$ Ibidem, p.239-47.

${ }^{32}$ I bidem. Também H ANSEN , J. A. "Ratio Studiorum e Política Católica I bérica no Século XVII". In: VIDAL, D. G.; HILSD ORF, M . L. S. (Org.) Tópicas em História da Educação. São Paulo: Edusp, 2001, p.13-41; FEROS, A. El Duque de Lerma... , op. cit. 
${ }^{33}$ HAN SEN, J. A., op. cit.

${ }^{34}$ Para uma introdução a questão, ver: NIGRO, S. S. "O Secretário". In: VILLARI, R. 0 homem barroco. Lisboa: Presença, 1995, p.81-93.

${ }^{35}$ CERIO L, F. F. El Concejo y Consejeros del Príncipe. Valencia: Institución Alfonso el M agnanimo, 1952, p.109.

${ }^{36}$ TOM ASY VALIENTE, F., op. cit., p.7.

${ }^{37}$ "Copia de lo que Su M ajestad ordenó al Concejo de Estado por Cédula de 1612 tocante al duque de Lerma", citado em TOM ASY VALIENTE, F., op. cit., Apéndice I, p.161.

${ }^{38}$ TOM ASY VALIENTE, F., op. cit., p.71.

${ }^{39}$ FEROS, A. El D uque de Lerma..., op. cit.

${ }^{40}$ BENIGNO, F., op. cit., p.3-36.

${ }^{41}$ TOM ASY VALIENTE, F., op. cit., p.14.

${ }^{42}$ FEROS, A., op. cit.

${ }^{43}$ M AVARAVALL, J. A., op. cit., p.275-6.

${ }^{44}$ RIVADENEIRA, P. P. de. Tratado de la Religión y Virtudes que debe tener el Príncipe Cristiano para gobernar y conservar sus Estados. Contra lo que $\mathrm{N}$ icolas Maquiavelo y los políticos de este tiempo enseñan. M adrid: P. M adrigal, 1595, p.593. A pud. M ARAVALL, J. A., op. cit., p.279.

${ }^{45}$ M ADARIAGA, Fr. J. de. Del Senado y su Príncipe. Valencia: Felipe M ey, 1617, p.2.

${ }^{46}$ SKIN N ER, Q ., op. cit., v.II, p.181-91.

${ }^{47}$ M ARAVALL, J. A. La Cultura del Barroco. Barcelo: Ariel, 1990, p.55-128.

${ }^{48}$ PACH AM , B. Fábula de Planetas, moralizada com varia doutrina política, ética e econômica. Lisboa: D om Lopes Rosa, 1643.

${ }^{49}$ RIBEIRO, J. P. Lustre ao D esembargo do Paço. Lisboa: Paulo Creesbeeck, 1649.

${ }^{50}$ COVARRU BIASY OROZCO, S. de, op. cit., p.931.

${ }^{51}$ PEDRAZA, F. B. de. El Secretario del Rey. Madrid: Luis Sanches Impr., 1620, p.15-6.

${ }^{52}$ THOM PSON, A. A. "El contexto Institucional de la Aparicion del M inistro-Favorito". In: ELLIOTT \& BROCKLISS, op. cit., p.25.

${ }^{53}$ I bidem, p.28.

${ }^{54}$ PECK, L. L. "El monopolio del favor: estructuras de poder en la Cortel nglesa de comienzos del Siglo XVII". In: ELLIOTT \& BROCKLISS, op. cit., p.81-104. 
${ }^{55}$ FAJARD O, D. de S. "I dea de um Principe Politico-Cristiano, Representada en Cien Empresas". In: 0 bras de D on D iego Saavedra Fajardo. M adrid: Real Academia Española /Atlas, 1947, p.129.

${ }^{56}$ THOM PSON, A. A., op. cit., p.36.

${ }^{57}$ QUEVEDO Y VILLEGAS, Don F. de. "Cómo ha de ser el Privado". In: 0 bras completas. Madrid: Aguilar, Tomo II, 1988, p.594.

${ }^{58}$ FAJARDO, D. deS., op. cit., p.132.

${ }^{59}$ Ibidem, p.133. 0 Pe. Raphael Bluteau, no Vocabulário, faz ecoar este juízo de Saavedra Fajardo, comum a muitos outros pensadores da época, dizendo: "advirta o valido, que os favores que logra, são fortunas do mar, \& ventos furiosos, que não a pressão a viagem, mas o naufrágio. Para o súdito, a graça do heágua do Nilo; beba-a de corrida, porque se se detiver, crocodilos o comerão". Op. cit., Tomo III, p.108.

${ }^{60}$ TOM ASY VALIENTE, F., op. cit., p.32. 